\title{
VICTIM IDENTIFICATION, FRAMING HEURISTIC AND STRESS \\ EFFECTS ON THE DONATION DECISION
}

\author{
Dr.Sc. Nihan TOMRİS KÜÇÜN (i) 1* \\ Dr. Sc. Sezen GÜNGÖR (iD) 2 \\ 1 Eskişehir Osmangazi University, Cognitive-Behavioral Application and Research Center Service TERMS, nihan_tomris@hotmail.com, \\ * Correspondent Author \\ 2 Tekirdag Namık Kema University, Çorlu Vocational School, Business Administration Department, sezengungor@nku.edu.tr
}

\begin{abstract}
Article history:
Accepted 12 July 2020

Available online 31 August 2020

\section{Keywords:}

Donation,

Framing Effect,

İdentifiable and Statistical,

Victims,

Galvanic Skin Response.

A b s t r a c t

The tendency of an individual to share his beings with other people arises from the social aspect of human nature. Especially in today's conditions where the gap between advantageous and disadvantaged groups is getting deeper, donation is extremely important to reach a global level of welfare and to create fair living standards for all. Due to the stated priorities, donation behavior has an important place among both religious and moral values. However, the factors that lead an individual towards donation behavior are not only social rules. In addition to external factors, important internal factors such as emotions also play a big role in the donation decision. In addition, there are many variables such as the donated thing itself, total assets of the donor and indeed the characteristics of the donor. Donation behavior, which is widely examined in the literature, is also considered as an important decision making subject.
\end{abstract}

In our study, the effects that motivate an individual towards a donation; along with the donation amount and the ratio of donation, were examined with framing heuristics which express the individual's knowledge of the victim. The mentioned variables were associated with stress as one of the strongest negative arousal output, to understand the emotional aspect of a donation decision. The stress levels of the participants, who manipulated by two different scenarios, were monitored with galvanic skin response to determine the decision-making scenarios which triggered stress. As a result; it has been found that the individual's effort to gain the money he donates and the features of the donation call significantly affect the decision.

\section{Introduction}

A donation is giving tangible and intangible assets without waiting in return for those in need to create social benefit and fulfil individual social responsibility (Kılıçalp Iaconantonio, 2013). This behavior, which reduces the devastating consequences of injustice in income distribution, strengthens social unity and forms the basis of social solidarity, is motivated by both internal (Bennett, 2003) and external (Bekkers and Wiepking, 2011) motivations. External factors that motivate an individual to donate; the credibility of the donor institution/individual (Amos, 1982), belief that it will be useful
(Bennett, 2003) and even cultural and social norms (Woo, 1992) are extremely effective as external triggers.

Additionally, internal mechanisms that direct an individual to a donation has great importance on the decision and continuity of the donation. In the donation literature, the origins of psychographic factors that form internal triggers are generally examined in two main axes, namely empathy (Batson et al., 1988) and egoism which is associated with the desire to resolve negativity (Cialdini et al., 1997).

Although the literature on donation and determining factors (Fisher and Ackerman 1998; Smith and McSweeney, 2007) are 
fairly extensive, studies to determine the emotions that affect individuals' donation attitudes and their formation are extremely limited (Kaufmann, 1970; Webb et al., 2000). However, analyzing the sub-components of attitudes is extremely important for understanding how donation behavior is shaped. Moreover, the fact that emotions have a very determining effect on people's decision-making process requires understanding the emotions experienced during donation.

Based on the stated importance and priorities, identifiable victim and framing effects on donation behavior were searched via participants' stress levels during donation as one of the psychophysiological responses. Thus, we achieved the results regarding both donation behavior and the participant's stress levels triggered by the stimuli. We believe that the studies conducted to understand the underlying mechanisms of behavioural triggers and emotion -including this study- could make an important contribution to the decision-making field.

\section{Donation}

The decision of an individual to sacrifice anything valuable to him to make social or personal goodness is a donation. There are two basic types of donation: in cash and in kind. Besides; donations such as blood, tissue and organs are also seen. But all donations usually have a common aim; to help someone and to create goodness for all.

Third Sector Foundation of Turkey (TUSEV) publishes yearly reports about Turkish people's donation behaviour (Çarkoğlu ve Aytaç, 2016). The last report of states that;

- $\quad$ The sum of all help and donations made in Turkey in a year, 228 TL per person (which corresponds to $0.8 \%$ of GDP) and the amount which was made through institutions of these were determined to be $16.7 \mathrm{TL}$ per donation.

- The word "charity" was perceived as "helping the poor and the people in need" by the $40,6 \%$ of the participants and perceived as "helping others and doing something good" by $28,5 \%$ of them.

- As the reason for the donation behavior, $32.5 \%$ of the participants chose religious reasons, $20.4 \%$ traditions, $14.2 \%$ the feeling of indebtedness towards the society and $12.7 \%$ personal satisfaction.

- "When asked to the participants whom they would like to help; participants mostly chose their relatives $(37 \%)$. The least desire for help was reported to someone who does not share the political view of the participant (2\%).
According to the CAF World Giving Index- 2018 report which is published by Charities Aid Foundation, Turkey' rank about donation is 131 between 146 countries. Indonesia is the first in the very same list. Donation and charity are defined in three groups in the report; helping others, a donation to a civil organization and spending time for a charity (CAF World Giving Index, 2018).

When we take into consideration the studies on donation decision, it is seen that besides the donation amount, the characteristics of the people or groups donated and the way these people are introduced to potential donors are also noteworthy. For example, if a call for help we face on social media also gives detailed information about the victim's dramatic story, our degree of empathy and the likelihood of deciding to make a donation for the needy person will increase. However, if a group of people and their needs are mentioned and these needs are presented to us statistically rather than empathically, we are less likely to be donors. These two different conditions are named as "identifiable victim effect" and "statistical victims" in the literature of donation (Anik et al., 2014).

\subsection{Identifiable Victims and Statistical Victims}

Identifiable victim effect refers to the rate of the needy people to the whole community. For example, if you are told that a family with 10 people are at death's door because of hunger and all members of this family will die if not helped, this condition will cause greater sensitivity due to the phenomenon "identifiable victims". On the other hand, if it is said that there are 1.000 people affected by infectious disease and 10 of them will die if they are not helped this is statistical knowledge and the sensitivity to those 10 people who are on the threshold of death will be relatively less. Identifiable victim researches show that if we know more about the victims we'll be more likely to spend time, money and effort for them. As Schelling (1968: 132) states, "the more we know, the more we care". Besides, the provided information about identifiable victims reveals subject's inferences related to the victims' "vitality" and "affinity". It is possible to briefly summarize the states of vitality and affinity as follows:

Scenario 1: In a Western African country Guinea, a two-year-old boy got the Ebola virus from a bat and is waiting for help. If he is not helped, the Ebola virus will spread many countries of the world as it is highly contagious and will cause thousands of people to die.

Scenario 2: A two-year-old boy living with his mother, brother, and grandmother in a West African country Guinea got Ebola virus from a bat which entered his dilapidated adobe house. Now, 
he can't reach the cure because of poverty and impossibilities. The nearest hospital is hundreds of miles away from his village and even he achieves to go to the hospital, it is very difficult to reach the medicines and equipment needed for treatment, because Guinea is a country struggling with complete destitution and misery. If he is not helped, the world may face a new Ebola outbreak. It is expected initially to spread to local and foreign health personnel in Guinea and then sadly it will rapidly spread to many countries. Due to Turkey's tourism potential, it could be said that Turkey will be one of the first countries that Ebola will spread.

In the first scenario, the donor doesn't have a clue about the victim's story. So that it is really difficult to feel empathy. Oppositely in the second scenario, the victim is presented to the donor with more vivid details. Thus the donor can feel the victim's misery almost vitally. The other catching point of the second scenario the mention to Turkey. Thanks to the affinity effect, if the donor is a Turkish citizen, that scenario will make him think about the big risk for once at least. Those effects may determine the donated amount for the victim or the number of donors involved.

In addition to all these variables, we believe that it is important to note that; there isn't just one correct answer for all. And, donating more to identifiable victims, but donating less to statistical victims can not be named as bias. Because it is not possible to define the "correct" financial value for a human being's life. Additionally, there is no verity mathematical formula for the donation amount. Bias is a concept that helps define people's inconsistent behavior, and there can be no consistent or inconsistent behavior in valuing a life (Small et al., 2005).

\section{Framing Heuristics}

Identifying victims in donation behavior is not accepted as a bias. However, in the decision-making field there are some common heuristics that people are influenced by. One of these heuristics is the "framing effect".

Framing is a concept that includes the details of how a subject is presented to individuals. Many sources on the presentation of alternatives mention an example of a driver's license and an organ donor. Accordingly, in the United States, a driver must sign a form to become an organ donor while obtaining his driving license. This is a preferential participation. However, the researches show that only $25 \%$ of the drivers who have received a driving license want to become organ donors. On the other hand, the situation maintains oppositely in countries such as Austria, Sweden and France. In other words, anyone who receives a driver's license is considered an organ donor. If you do not want to be a donor, you must fill out a form. This is also called unpreferential participation. Also, related researches show that the rate of participation in organ donation in these countries is more than $90 \%$ (Nofsinger, 2011).

It is possible to frame a decision-making problem in different ways. Tversky and Kahneman (1981) showed in their experiments at Stanford University and British Columbia University that different results can be obtained by framing a problem in different ways. In that experiment, which is referred to the literature as "Asian Disease", two different scenarios with the same results are applied. According to the results, people can make decisions based on how a topic is presented to them. In other words, individuals evaluate information according to how it is transmitted to them. Also, they are likely to give different answers to the same questions, depending on how they are asked.

As a result, people's decision-making processes are open to the influence of many internal and external factors. Especially when it comes to sharing something valuable with another person both positive and negative emotions can be experienced like; empathy (Verhaert and Poel, 2011), satisfaction (Nguyen et al., 2008) happiness (Liu and Aaker, 2008), pride (Anjum and Gueth, 2019), regret (O'Carroll et al., 2011) stress (Ranganathan and Henley, 2008; Sollberger et al., 2016). Besides, the donated thing, how this thing is acquired, its amount, and the amount left to the individual in case of donation are other important determining variables (Havens et al., 2006). In summary, identifying the rational and irrational causes underlying donation behavior that requires a decision-making process is important also to understand the dynamics of the decision-making process.

\section{Use of Neurometric and Biometric Methods in Decision Making Research}

Decision-making studies find itself a wide range of applications in social sciences' branches (psychology (Hastie and Daves, 2009), finance (Steuer and $\mathrm{Na}, 2003$ ), marketing (Keegan and Rowley, 2017)) just like in natural and applied sciences (Yu et al., 2017; Mosier and Skitka, 2018). Decision making, one of the most specific processes of human behavior, is shaped by many internal and external motivators. In addition to culture, environmental effects, norms, behavior patterns and many more sociological dynamics (Bruch and Feinberg, 2017), the individual's current attitudes and emotions (Rubenking, 2019) have a major impact on the process.

Qualitative (Hutchinson et al., 2018) and quantitative (Liao et al., 2017; Baker et al., 2017) approaches are both used separately or together in order to resolve the decision-making process. The complex nature of this process and the difficulty in the 
generalization phase require the use of more than one approach. In addition to the person's statement or the researcher's observations, the use of some neuroscience methods in decisionmaking studies provides an important advantage in order to examine the effect of emotions on the process closely and without being dependent on self-report. In addition to neurometric measurement devices that monitor the cognitive load of the brain such as EEG and fMRI; there are various devices that track other biometric responses such as eye-tracking, electromyography (EMG), electrocardiography (ECG), galvanic skin response (GSR) etc.

GSR is one of the oldest methods used in emotion identification studies (Solnais et al., 2013); due to its important advantage in measuring somatic responses of the individual against the stimulus, it also offers important advantages to the researcher with its low cost, portable structure and practical use. In this study, the donation stress of the individual will be monitored with GSR within the scope of the effects described above. With GSR, it will be determined which effect caused more emotional arousal in the decision making processes of the participants.

\subsection{Galvanic Skin Response}

GSR is based on the principle of measuring electrical activity occurring on the skin surface. In an emotional state change, the sweat glands become active. Accordingly, the positive and negative ion balance changes on the skin surface. By tracking this change with GSR, it is possible to have information about the conscious/ unconscious process experienced by the individual. Briefly, GSR data is basically associated with emotional arousal. The disadvantage of GSR to the researcher is that this arousal cannot provide clear information about whether it is a positive or negative emotional arousal. GSR results are the autonomous response of the somatic nervous system. This change in skin conductivity is mostly associated with stress in the literature (Bakker et al., 2011; Villarejo et al., 2012; Kurniawan, 2013), and also with excitement describing a relatively positive stimulation (Zimny and Weidenfeller, 1962; Kucher et al., 2016; Cuesta et al., 2018). In order to clearly determine the arousal type, it is important either to use GSR integrated with other neuroscientific methods or to design the experiment model in a way that does not trigger the other emotional state.

\section{Experimental Design}

The sample of the research consists of 80 people. This sample was randomly divided into two and the experiment conducted with two groups of 40 people. Before starting the experiment, they were all informed about the experiment protocol and asked permission to collect biometric data.
The first group was named as "acquisition group". Researchers told the first group members that they will answer 5 mathematics questions with the chance to earn 2 TL for each correct answer.

The questions are as follows:

$$
\begin{aligned}
& 9 \mathrm{x} 8=72 \\
& (2+5) \times 3=21 \\
& (3+4) \times(5+6)=77 \\
& 3^{\wedge} 2+5^{\wedge} 2=34 \\
& \left(2^{\wedge} 3+3^{\wedge} 2\right) \times 4^{\wedge} 2=272
\end{aligned}
$$

The amount of money earned by the participants in the acquisition group is between 0 and $10 \mathrm{TL}$. After playing the math game separately with each member of the group and delivering the money they earned to all the group members, the experiment phase started. Evaluation of the mathematics questions was made in front of the participants and the answers were checked in detail. Thanks to this evaluation, the participants were aimed to feel that they really earned the money they received. A question was asked of 20 people who were selected randomly from the acquisition group, indicating their donation needs in which identifiable victims were described. In addition, 10 randomly selected among these 20 people were asked these questions with a "loss-frame", while the other 10 people were asked the same questions with a "benefit-frame". The other 20 participants of the group were asked a question indicating the donation needs in which statistical victims were described. Again, the same question was asked in the form of earnings, while the other 10 people were asked in the loss-frame, while 10 of them were chosen randomly. Basically, the participants were asked how much of the money they would donate with the amount of money they had just gained from the math game. It was also emphasized that they had the right to refuse to donate.

The participants in the second group of the study were named as "grant group". There were also 40 participants in that group and the same questions were asked exactly as in the first group. The only difference between the groups was that the grant group was asked simple math questions and $10 \mathrm{TL}$ was given immediately without checking the correct answers. It was not concealed from the participants that the math questions were not evaluated. In this way, we had them know that 10 TL was granted to them.

Schimmer 3 GSR unit was used to monitor the participants' skin conductivity responses. Two silver electrodes were positioned on the index and the middle finger of the hand that the participant did not use predominantly. The participant warned to stay still during the experiment. The room temperature was kept constant at $220 \mathrm{C}$ and a completely quiet environment was provided. In 
this way, environmental factors that would negatively affect the GSR data were prevented.

The data collected from the experiment were categorized as seen in the following titles:

- Participant Groups: Acquisition group and grant group

- Victim identification: Identifiable victim and statistical victim

- $\quad$ Framing Method: Loss -frame and benefit-frame

- Obtained amount: The amount of money that the participants earn or receive as a grant after simple mathematics questions (0-10 TL in the acquisition group, while it is $10 \mathrm{TL}$ for all participants in the grant group.)

- Donation amount: The amount expressing how much of the money the participant donate during the experiment.

- Donation ratio: The ratio of donation amount to the amount obtained

- $\quad$ GSR: Stres arousal $(\mu \mathrm{S})$

The hypotheses were organized according to this reporting are as follows:

H1= The donated amount significantly differs between acquisition and grant groups.

$\mathbf{H 2}=$ The donation ratio significantly differs between acquisition and grant groups.
H3= The donated amount significantly differs in terms of identifiable and statistical victims.

H4= The donation ratio significantly differs in terms of identifiable and statistical victims.

H5= The donated amount significantly differs between lossframe and benefit-frame.

H6= The donated ratio significantly differs between loss-frame and benefit-frame.

H7= Stress arousal level significantly differs between acquisition and grant groups.

H8= Stress arousal level significantly differs in terms of identifiable and statistical victims.

H9= Stress arousal level significantly differs between loss-frame and benefit-frame.

\section{Results}

Statistical analysis was conducted via SPSS Version 22 package program. Kolmogorov Smirnov test gave the result that the data did not show normal distribution. Accordingly, analyzes were continued with non-parametric tests. The confidence level of the analyzes was accepted as $95 \%$ and interpreted at $5 \%$ significance level.

Mann Whitney U Test was applied for the hypotheses and the results are reported in the Table 1.

Table 1. Statistical Analysis Results

\begin{tabular}{|c|c|c|c|c|c|c|c|}
\hline & GROUP & Mean & $\begin{array}{l}\text { Mean } \\
\text { Rank }\end{array}$ & $\begin{array}{l}\text { Sum of } \\
\text { Ranks }\end{array}$ & $\mathbf{U}$ & $\mathbf{Z}$ & $\mathbf{p}$ \\
\hline \multirow{6}{*}{ 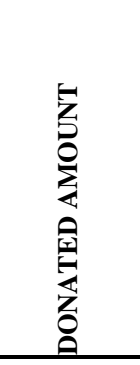 } & ACQUISITION GROUP & 3,63 & 35,18 & 1407 & \multirow{2}{*}{587} & \multirow{2}{*}{$-2,08$} & \multirow{2}{*}{$\mathbf{0 , 0 3 8}$} \\
\hline & GRANT GROUP & 4,75 & 45,83 & 1833 & & & \\
\hline & IDENTIFIABLE VICTIMS & 4,97 & 48,73 & 1949 & \multirow{2}{*}{471} & \multirow{2}{*}{$-3,21$} & \multirow{2}{*}{0,001} \\
\hline & STATISTICAL VICTIMS & 3,4 & 32,28 & 1291 & & & \\
\hline & BENEFIT-FRAME & 3,42 & 33,11 & 1324,5 & \multirow{2}{*}{505} & \multirow{2}{*}{$-2,88$} & \multirow{2}{*}{0,004} \\
\hline & LOSS-FRAME & 4,95 & 47,89 & 1915,5 & & & \\
\hline \multirow{6}{*}{ 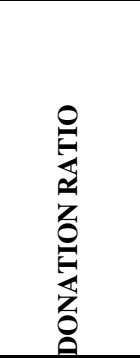 } & ACQUISITION GROUP & 0,55 & 44,96 & 1798,5 & \multirow{2}{*}{622} & \multirow{2}{*}{$-1,73$} & \multirow{2}{*}{0,083} \\
\hline & GRANT GROUP & 0,47 & 36,04 & 1441,5 & & & \\
\hline & IDENTIFIABLE VICTIMS & 0,6 & 49,75 & 1990 & \multirow{2}{*}{430} & \multirow{2}{*}{$-3,59$} & \multirow{2}{*}{$\mathbf{0 , 0 0 0}$} \\
\hline & STATISTICAL VICTIMS & 0,41 & 31,25 & 1250 & & & \\
\hline & BENEFIT-FRAME & 0,41 & 31,16 & 1246,5 & \multirow{2}{*}{427} & \multirow{2}{*}{$-3,63$} & \multirow{2}{*}{$\mathbf{0 , 0 0 0}$} \\
\hline & LOSS-FRAME & 0,61 & 49,84 & 1993,5 & & & \\
\hline \multirow{2}{*}{ 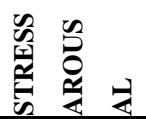 } & ACQUISITION GROUP & 645434,3 & 53,69 & 2147,5 & \multirow{2}{*}{273} & \multirow{2}{*}{$-5,08$} & \multirow{2}{*}{$\mathbf{0 , 0 0 0}$} \\
\hline & GRANT GROUP & 128524,6 & 27,31 & 1092,5 & & & \\
\hline
\end{tabular}




\begin{tabular}{|c|c|c|c|c|c|c|}
\hline IDENTIFIABLE VICTIMS & 590345,4 & 53,73 & 2149 & \multirow{2}{*}{271} & \multirow{2}{*}{$-5,09$} & \multirow{2}{*}{0,000} \\
\hline STATISTICAL VICTIMS & $-73485,72$ & 27,28 & 1091 & & & \\
\hline BENEFIT-FRAME & $-68969,75$ & 31,2 & 1248 & \multirow{2}{*}{428} & \multirow{2}{*}{$-3,58$} & \multirow{2}{*}{0,000} \\
\hline LOSS-FRAME & 584929,5 & 49,8 & 1992 & & & \\
\hline
\end{tabular}

As seen in the table $\mathrm{xx}$ the $\mathrm{H} 1$ hypothesis was accepted. So the donated amount differs between donor and grant groups. Accordingly, the average donation amount of the participants in the grant group (Mean $=4.75$ ) was significantly higher than the average of the donation amount (Mean $=3.63$ ) of the participants in the acquisition group $\left(\mathrm{U}\left(\mathrm{NK}_{\text {acquisitiongroup }}=40, \mathrm{~N}_{\text {grantgroup }}=40\right)=\right.$ $587.00, \mathrm{z}=-2.07, \mathrm{p}<.05)$.

The differentiation of identifiable victims and statistical victims in terms of the donated amount may also be seen in the same table. According to the analysis confirming the $\mathrm{H} 3$ hypothesis, the identifiable victims $($ Mean $=4.97$ ) got significantly more donations than the statistical victims $($ Mean $=3.40)(\mathrm{U}$ $\left(\mathrm{NK}_{\text {acquisitiongroup }}=40, \mathrm{~N}_{\text {grantgroup }}=40\right)$. The $\mathrm{H} 5$ hypothesis was also accepted. Accordingly, more donations were collected in cases of loss-frame conditions (Mean $=4.95$ ) than benefit-frame conditions (Mean $=3.42)\left(\mathrm{U}\left(\mathrm{NK}_{\text {acquisitiongroup }}=40, \mathrm{~N}_{\text {grantgroup }}=40\right)\right.$ $=504.50, \mathrm{z}=-2.88, \mathrm{p}<.05)$.

It was determined that the donation ratio calculated by proportioning the donated amount to the income obtained did not differ between the acquisition and grant groups ( $p>.05$ ). Therefore, the $\mathrm{H} 2$ hypothesis was rejected. However, a significant difference was found between identifiable victims and statistical victims at the donation ratio and the $\mathrm{H} 4$ hypothesis was accepted. Accordingly, donations made to identifiable victims (Mean $=.60)$ are proportionally higher than donations made to statistical victims $($ Mean $=.41)\left(\mathrm{U}\left(\mathrm{NK}_{\text {acquisitiongroup }}=40, \mathrm{~N}_{\text {grantgroup }}=40\right)=\right.$ 430.00, $\mathrm{z}=-3.593, \mathrm{p}<.05)$. H6 hypothesis was also accepted. Accordingly, the donation requests $($ Mean $=.61)$ to which lossframe was applied are higher than the donation requests $($ Mean = $.41)$ to which benefit-frame was applied $\left(\mathrm{U}\left(\mathrm{NK}_{\text {acquisitiongroup }}=40\right.\right.$, $\left.\left.\mathrm{N}_{\text {grantgroup }}=40\right)=426.50, \mathrm{z}=-3.627, \mathrm{p}<.05\right)$.

Finally, according to the GSR results, which represents the stress levels of the participants, significant differences were found in terms of both the participant groups, victim identification and framing method. In terms of the participant group, the stress levels of the participants in the GSR results acquisition group (Mean $=645434,32)$ were higher than the participants in the grant group $($ Mean $=-128524,62)\left(\mathrm{U}\left(\mathrm{NK}_{\text {acquisitiongroup }}=40, \mathrm{~N}_{\text {grantgroup }}=\right.\right.$ 40) $=272.500, \mathrm{z}=-5.076, \mathrm{p}<.05)$. This indicates that individuals in the acquisition group were exposed to more stress when donating. The level of stress was lower in the participants in the grant group. According to the results, the $\mathrm{H} 7$ hypothesis is confirmed. From the point of view of the participant group, it was determined that the participants were exposed to more stress in donations to the detectable victims $($ Mean $=590345.42)$ than the statistical victims (Mean $=-73485.72)\left(\mathrm{U}\left(\mathrm{NK}_{\text {acquisitiongroup }}=40\right.\right.$, $\left.\left.\mathrm{N}_{\text {grantgroup }}=40\right)=271.00, \mathrm{z}=-5.091, \mathrm{p}<.05\right)$. Accordingly, the H8 hypothesis was accepted. Lastly, in terms of the framing method, it was seen that the participants were exposed to more stress in the demand requests presented with the loss framing $($ Mean $=584929,45)$ compared to the demands presented with the benefit framing (Mean $=-68969,75)$. This result shows us that the $\mathrm{H} 9$ hypothesis was also accepted $\left(\mathrm{U}\left(\mathrm{NK}_{\text {acquisitiongroup }}=40\right.\right.$, $\left.\left.\mathrm{N}_{\text {grantgroup }}=40\right)=428.050, \mathrm{z}=-3.580, \mathrm{p}<.05\right)$.

\section{Discussion}

The results of Kogut and Ritov (2005), proves that people tend to donate more to identifiable victims than to victims that have not been identified and remained just as statistical data. The researchers state that if an identified victim and a group of identified victims are mentioned, an identified victim gets more donation than the identified victim group. But oppositely if an unidentified victim and a group of unidentified victims mentioned then the victim group get more donations. In other words, the donation to a single victim among identified victims may be higher than the donation to a group of victims. On the other hand, if victims are unidentified (statistical victims); donation to a single victim is lower than than the donation to a group of victims. These results are consistent with the studies showing that more donations were made to identifiable victims in terms of donation amount. Accordingly, our research, when a choice was made between an identifiable victim and an identifiable group of victims the participants wanted to donate more to a single victim. A similar study conducted by Schelling in 1968, reveals that people tend to donate more to identifiable victims when it gets to the point to save a human being's life. Similar results were also obtained by Small and Loewenstein (2003a, 2003b). In that study, a similar result was obtained between identifiable victims and statistical victims. Accordingly, identifiable victims trigger more emotional arousal than to the statistical victims. GSR results also support that statement. In our study in the case of identifiable victims, participants' stress levels significantly increased to the other group. This stress-related arousal can be explained by the emotional responses cited in both Small and Loewenstein's work. In other words, the participants showed more emotional reactions 
to identifiable victims. The study briefly shows that the decision to donate has both cognitive and emotional sub-dynamics. It is obvious that the importance of using all the relevant elements together in the donation campaigns established in order to create value either for a single person or for the whole population, to reproduce by sharing the existing wealth with others and to achieve global prosperity.

\section{References}

1. Amos, O. M. (1982). Empirical analysis of motives underlying individual contributions to charity. Atlantic Economic Journal, 10(4), 45-52.

2. Anik, L., Norton, M. I., \& Ariely, D. (2014). Contingent match incentives increase donations. Journal of Marketing Research, 51(6), 790-801.

3. Anjum, G., \& Gueth, W. (2019). Becoming generous and respecting honor: An experiment based on donation and trust-game with multiple trustees. IBA Business Review, 14(2).

4. Baker, C. L., Jara-Ettinger, J., Saxe, R., \& Tenenbaum, J. B. (2017). Rational quantitative attribution of beliefs, desires and percepts in human mentalizing. Nature Human Behaviour, 1(4), 1-10.

5. Bakker, J., Pechenizkiy, M., \& Sidorova, N. (2011, December). What's your current stress level? Detection of stress patterns from GSR sensor data. In 2011 IEEE 11th international conference on data mining workshops (pp. 573-580). IEEE.

6. Batson, C. Daniel, Janine L. Dyck, J. Randall Brandt, Judy G. Batson, Anne L. Powell, M. Rosalie McMaster, and Cari Griffitt (1988), "Five Studies Testing Two New Egoistic Alternatives to the Empathy-Altruism Hypothesis," Journal of Personality and Social Psychology, 55 (July), 52-77.

7. Bekkers, R., \& Wiepking, P. (2011). A literature review of empirical studies of philanthropy: Eight mechanisms that drive charitable giving. Nonprofit and voluntary sector quarterly, 40(5), 924-973.

8. Bennett, R. (2003). Factors underlying the inclination to donate to particular types of charity. International Journal of Nonprofit and Voluntary Sector Marketing, 8, 12-29.

9. Bruch, E., \& Feinberg, F. (2017). Decision-making processes in social contexts. Annual review of sociology, 43, 207-227.

10. Cialdini, R. B., Brown, S. L., Lewis, B. P., Luce, C., \& Neuberg, S. L. (1997). Reinterpreting the empathyaltruism relationship: When one into one equals oneness. Journal of Personality and Social Psychology, 73, 481-494. 11. Cuesta, U., Martínez-Martínez, L., \& Niño, J. I. (2018). A case study in neuromarketing: Analysis of the influence of music on advertising effectivenes through eyetracking, facial emotion and GSR. European journal of social science education and research, 5(2), 73-82.

12. Çarkoğlu, A., \& Aytaç, S. E. (2016). Individual giving and philanthropy in Turkey. Istanbul: Third Sector Foundation of Turkey.

13. Fisher, R. J., \& Ackerman, D. (1998). The effects of recognition and group need on volunteerism: A social norm perspective. Journal of consumer research, 25(3), 262-275.

14. Hastie, R., \& Dawes, R. M. (2009). Rational choice in an uncertain world: The psychology of judgment and decision making. Sage Publications.

15. Havens, J. J., O’Herlihy, M. A., \& Schervish, P. G. (2006). Charitable giving: How much, by whom, to what, and how. The nonprofit sector: A research handbook, 2, 542-567.

16. Hutchinson, M., Hurley, J., Kozlowski, D., \& Whitehair, L. (2018). The use of emotional intelligence capabilities in clinical reasoning and decision-making: A qualitative, exploratory study. Journal of clinical nursing, 27(3-4), e600-e610.

17. Kaufmann, H. (1970). Aggression and altruism: A psychological analysis. Holt McDougal.

18. Keegan, B. J., \& Rowley, J. (2017). Evaluation and decision making in social media marketing. Management Decision.

19. Kılıçalp Iaconantonio, S. (2013) Bireysel Bağışçılar için Rehber ve İlham Veren Bağışçı Öyküleri, İstanbul: Türkiye Üçüncü Sektör Vakfi (TÜSEV)

20. Kogut, T., \& Ritov, I. (2005). The singularity effect of identified victims in separate and joint evaluations. Organization Behavior and Human Decision Process, 97, 106-116.

21. Kucher, K., Cernea, D., \& Kerren, A. (2016, March). Visualizing excitement of individuals and groups. In Proceedings of the 2016 EmoVis Conference on Emotion and Visualization (pp. 15-22).

22. Kurniawan, H., Maslov, A. V., \& Pechenizkiy, M. (2013, June). Stress detection from speech and galvanic skin response signals. In Proceedings of the 26th IEEE International Symposium on Computer-Based Medical Systems (pp. 209-214). IEEE.

23. Liao, Z., Jiang, L., \& Wang, Y. (2017, May). A quantitative measure of regret in decision-making for human-robot collaborative search tasks. In 2017 American Control Conference (ACC) (pp. 1524-1529). IEEE.

24. Liu, W., \& Aaker, J. (2008). The happiness of giving: The time-ask effect. Journal of consumer research, 35(3), 543-557. 
25. Moll, J., Krueger, F., Zahn, R., Pardini, M., de Oliveira-Souza, R., \& Grafman, J. (2006). Human frontomesolimbic networks guide decisions about charitable donation. Proceedings of the National Academy of Sciences, 103(42), 15623-15628.

26. Mosier, K. L., \& Skitka, L. J. (2018). Human decision makers and automated decision aids: Made for each other?. In Automation and human performance (pp. 201-220). Routledge.

27. Nguyen, D. D., DeVita, D. A., Hirschler, N. V., \& Murphy, E. L. (2008). Blood donor satisfaction and intention of future donation. Transfusion, 48(4), 742-748.

28. Nofsinger, John. "The Psychology of Investing (Pearson Series in Finance)" 3th Edition", 2011

29. O'Carroll, R. E., Dryden, J., Hamilton-Barclay, T., \& Ferguson, E. (2011). Anticipated regret and organ donor registration-A pilot study. Health Psychology, 30(5), 661. 30. Ranganathan, S. K., \& Henley, W. H. (2008). Determinants of charitable donation intentions: a structural equation model. International journal of nonprofit and voluntary sector marketing, 13(1), 1-11.

31. Rubenking, B. (2019). Emotion, attitudes, norms and sources: Exploring sharing intent of disgusting online videos. Computers in Human Behavior, 96, 63-71.

32. Schelling, T. C. (1968). The life you save may be your own. In S. Chase (Ed.), Problems in public expenditure analysis. Washington, DC: The Brookings Institute.

33. Small, D. A., \& Loewenstein, G. (2003a). Helping a victim or helping the victim: altruism and identifiability. Journal of Risk and Uncertainty, 26(1), 5-16.

34. Small, D. A., \& Loewenstein, G. (2003b). The devil you know: the effects of identifiability on punitiveness. Manuscript.

35. Small, D. A., Loewenstein, G., \& Slovic, P. (2005). Can insight breed callousness? The impact of learning about the identifiable victim effect on sympathy. Unpublished manuscript.

36. Smith, J. R., \& McSweeney, A. (2007). Charitable giving: The effectiveness of a revised theory of planned behaviour model in predicting donating intentions and behaviour. Journal of Community \& Applied Social Psychology, 17(5), 363-386.

37. Sollberger, S., Bernauer, T., \& Ehlert, U. (2016). Stress influences environmental donation behavior in men. Psychoneuroendocrinology, 63, 311-319.

38. Solnais, C., Andreu-Perez, J., Sánchez-Fernández, J., \& Andréu-Abela, J. (2013). The contribution of neuroscience to consumer research: A conceptual framework and empirical review. Journal of Economic Psychology, 36, 68-81.
39. Steuer, R. E., \& Na, P. (2003). Multiple criteria decision making combined with finance: A categorized bibliographic study. European Journal of operational research, 150(3), 496-515.

40. Tversky, A., \& Kahneman, D. (1981). The framing of decisions and the psychology of choice. science, 211(4481), 453-458.

41. Verhaert, G. A., \& Van den Poel, D. (2011). Empathy as added value in predicting donation behavior. Journal of Business Research, 64(12), 1288-1295.

42. Villarejo, M. V., Zapirain, B. G., \& Zorrilla, A. M. (2012). A stress sensor based on Galvanic Skin Response (GSR) controlled by ZigBee. Sensors, 12(5), 6075-6101. 43. Webb, D. J., Green, C. L., \& Brashear, T. G. (2000). Development and validation of scales to measure attitudes influencing monetary donations to charitable organizations. Journal of the academy of marketing science, 28(2), 299309.

44. Woo, K. T. (1992). Social and cultural aspects of organ donation in Asia. Annals of the Academy of Medicine, Singapore, 21(3), 421-427.

45. Yu, H., Shen, Z., Miao, C., Leung, C., Chen, Y., Fauvel, S., ... \& Yang, Q. (2017). A dataset of human decision-making in teamwork management. Scientific data, 4(1), 1-12.

46. Zimny, G. H., \& Weidenfeller, E. W. (1962). Effects of music upon GSR of children. Child Development, 891896. 